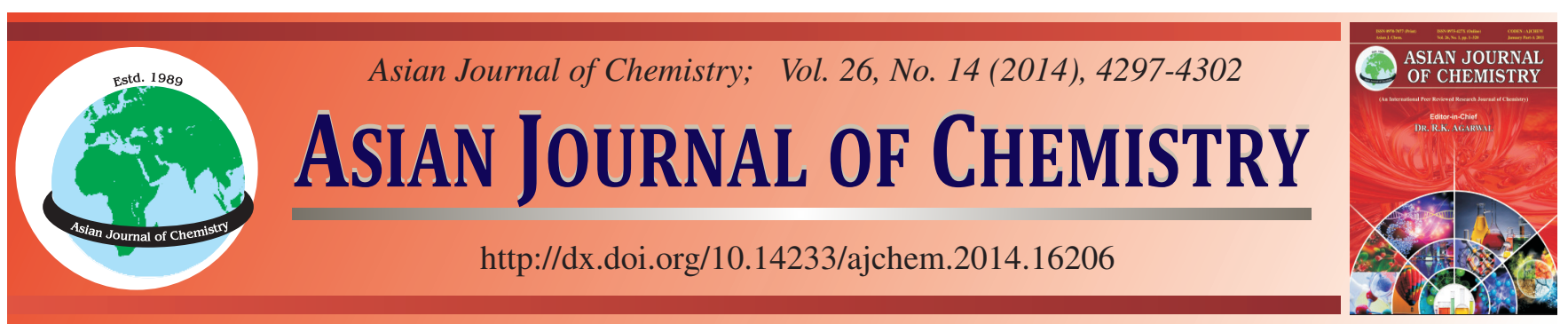

\title{
Preparation of Expandable Graphite Intercalated by Sulfuric Acid and Sodium Silicate and Its Flame Retardancy Application for Ethylene Vinyl Acetate Copolymer
}

\author{
Xiu-Yan Pang ${ }^{*}$, Yu Tian, Zhi-Xiao Zhai and Ming-Wei Duan
}

College of Chemistry and Environmental Science, Hebei University, Baoding 071002, P.R. China

*Corresponding author: E-mail: pxy833@163.com

Received: 19 August 2013;

Accepted: 20 December 2013;

Published online: 5 July 2014;

AJC-15462

\begin{abstract}
Expandable graphite intercalated by sulfuric acid and sodium silicate $\left(\mathrm{Na}_{2} \mathrm{SiO}_{3}\right)$ was prepared by two step intercalation method under oxidation of $\mathrm{KMnO}_{4}$. The influence of various factors on dilatability of the expandable graphite were discussed including the dosages of $\mathrm{KMnO}_{4}, \mathrm{H}_{2} \mathrm{SO}_{4}, \mathrm{Na}_{2} \mathrm{SiO}_{3} \cdot 9 \mathrm{H}_{2} \mathrm{O}$ and $\mathrm{H}_{2} \mathrm{SO}_{4}$ concentration, $\mathrm{pH}$ of $\mathrm{Na}_{2} \mathrm{SiO}_{3}$ and $\mathrm{NaOH}$ mixed solution, reaction temperature, reaction time. Expandable graphite with an initial expansion temperature of $202{ }^{\circ} \mathrm{C}$ and expansion volume of $517 \mathrm{~mL} / \mathrm{g}$ could be prepared under the mass ratio C: $\mathrm{KMnO}_{4}: \mathrm{H}_{2} \mathrm{SO}_{4}(98 \%): \mathrm{Na}_{2} \mathrm{SiO}_{3} \cdot 9 \mathrm{H}_{2} \mathrm{O}$ of 1.0:0.22:4.0:0.8. $\mathrm{H}_{2} \mathrm{SO}_{4}$ should be diluted to mass concentration of $75 \%$ before intercalation, $\mathrm{Na}_{2} \mathrm{SiO}_{3}$ dissolved in $\mathrm{NaOH}$ aqueous solution with a pH of 13 was dropwise added when the intercalation of $\mathrm{H}_{2} \mathrm{SO}_{4}$ preceded $7.5 \mathrm{~min}$ and the reaction was totally maintained $40 \mathrm{~min}$ at $40^{\circ} \mathrm{C}$. X-ray powder diffraction analysis was performed to illuminate the structure characteristics of expandable graphite and its flame retarding property for ethylene vinyl acetate copolymer (EVA) was investigated and characterized by limiting oxygen index (LOI) and scanning electron microscope. The LOI of EVA is only $19.3 \%$; addition of $30 \%$ expandable graphite made the LOI of EVA/expandable graphite reaches $28.4 \%$, but the addition of same dosage of compared blank expandable graphite only get a LOI of $24.4 \%$. The excellent anti-flame capability of expandable graphite is owing to its fully endothermic expansion and formation of heat insulation swollen multicellular char.
\end{abstract}

Keywords: Expandable graphite, Silicate, Dilatability, Intumescent flame retardant, Ethylene vinyl acetate copolymer.

\section{INTRODUCTION}

Graphite is a crystal compound with graphene planes structure bonded by van der Waals force and the bond energy is only $16.7 \mathrm{~kJ} / \mathrm{mol}$. Under oxidation, many compounds can intercalate graphene planes and then graphite intercalation substances called expandable graphite can be prepared ${ }^{1,2}$. Expandable graphite has many uses: it has catalysis in the reaction of organic acid and alcohol ${ }^{3}$; Porous expanded graphite adsorbent can be prepared with expandable graphite expanding instantly at high temperature ${ }^{4}$. The expandable graphite is an intumescent type flame retardant, a char-forming agent, a blowing agent and smoke suppressant ${ }^{5-8}$. Due to its outstanding anti-flame capability, expandable graphite has been used widely in the flame retarded polymers such as polyolefin blends ${ }^{9}$, polylactide ${ }^{10}$, polyurethane ${ }^{11}$ and poly (methyl methacrylate $)^{12}$.

In its traditional preparation methods, the mainly used intercalating agent is $\mathrm{H}_{2} \mathrm{SO}_{4}$ for its dual function i.e., as a donor of $\mathrm{H}^{+}$and intercalating agent, low-price, easy and simple to handle, high dilatability of the prepared product ${ }^{13,14}$. However, the use of it leads to high sulfur content in products and corrosion of storage devices caused by lixiviating vitriol. So, it is necessary to supplement assistant intercalating agent to replace part of $\mathrm{H}_{2} \mathrm{SO}_{4}{ }^{15,16}$. The most remarkable thing is that if a traditional flame retardant is used as assistant intercalating agent, it is not only can decrease sulfur content in graphite intercalation substances, but also improve its flame retardant property. For examples, expandable graphite, intercalated by $\mathrm{H}_{2} \mathrm{SO}_{4}$ and ammonium polyphosphate (APP) by two-step method, showed higher expansion volume than the product intercalated by single $\mathrm{H}_{2} \mathrm{SO}_{4}{ }^{17}$; expandable graphite, intercalated by $\mathrm{H}_{2} \mathrm{SO}_{4}$ and $\mathrm{Na}_{4} \mathrm{P}_{2} \mathrm{O}_{7}$ with direct method, presented excellent dilatability and combustion limiting oxygen index than the compared single $\mathrm{H}_{2} \mathrm{SO}_{4}$ intercalation substance ${ }^{18}$. Silicate is a kind of well-known flame retardant with good flame retardancy for its formation of $\mathrm{SiO}_{2}$ protective layer on composite surface ${ }^{19,20}$. As far as little study is reported about preparation of expansible graphite (EG) using $\mathrm{H}_{2} \mathrm{SO}_{4}$ and silicate as main intercalating agent and assistant intercalating agent, respectively.

The purpose of this research is to prepare a high dilatability and combined intumescent flame retardant expandable graphite through chemical intercalation reaction of graphite using $\mathrm{H}_{2} \mathrm{SO}_{4}$ and $\mathrm{Na}_{2} \mathrm{SiO}_{3}$ as intercalating agent. Due to the poor solubility of silicate in acid medium, $\mathrm{Na}_{2} \mathrm{SiO}_{3}$ dissolved 
in $\mathrm{NaOH}$ aqueous solution was used. At the same time, a twostep intercalating method was performed to ensure oxidation of $\mathrm{KMnO}_{4}$ and preferentially intercalation of $\mathrm{H}_{2} \mathrm{SO}_{4}$. Expansion property and structure characteristics of the prepared expandable graphite were characterized by expanded volume (EV) and initial expansion temperature. Influence of various factors on dilatability of the expandable graphite were detected including the dosages of $\mathrm{KMnO}_{4}, \mathrm{H}_{2} \mathrm{SO}_{4}, \mathrm{Na}_{2} \mathrm{SiO}_{3} \cdot 9 \mathrm{H}_{2} \mathrm{O}$ and $\mathrm{H}_{2} \mathrm{SO}_{4}$ concentration, $\mathrm{pH}$ of $\mathrm{Na}_{2} \mathrm{SiO}_{3}$ and $\mathrm{NaOH}$ mixed solution, reaction temperature, reaction time. X-ray diffraction (XRD) was performed to characterize the crystal structure of expandable graphite. Its flame retarding property for ethylene vinyl acetate copolymer (EVA) was investigated and characterized by limiting oxygen index (LOI) and scanning electron microscope (SEM).

\section{EXPERIMENTAL}

SX3-4-13 Muffle furnace (Tientsin, China. precision of temperature $\pm 0.1-0.4 \%{ }^{\circ} \mathrm{C}$ ), 101-3 Oven (Shanghai, China. precision of temperature $\pm 2{ }^{\circ} \mathrm{C}$ ), Muller (Jiangsu, China), Y-4Q X-ray diffractometer (Dandong, China), Muller (Jiangsu, China), JF-3 Limiting oxygen index (LOI) instrument (Chengde, China) and TM3000 electron microscope (Japan) were used in this experiment.

Natural flake graphite with a carbon content of $95 \%$ was provided by Action Carbon CO. LTD, Baoding, China; and an average flake size is $0.18 \mathrm{~mm}$. Ethylene vinyl acetate copolymer was purchased from Tianjin, China. $\mathrm{Na}_{2} \mathrm{SiO}_{3} \cdot 9 \mathrm{H}_{2} \mathrm{O}$, $\mathrm{H}_{2} \mathrm{SO}_{4}(98 \%), \mathrm{NaOH}$ and $\mathrm{KMnO}_{4}$ are all analytical agents.

Preparation of expandable graphite: At first, the quantified reactants were mixed in a $250 \mathrm{~mL}$ beaker in the order of diluted $\mathrm{H}_{2} \mathrm{SO}_{4}$, natural graphite $\mathrm{C}, \mathrm{KMnO}_{4}$. The mixture was stirred at a definite temperature controlled with water bath. Then mixture of $\mathrm{Na}_{2} \mathrm{SiO}_{3}$ and aqueous solution of $\mathrm{NaOH}$ with a certain $\mathrm{pH}$ was added dropwise when the intercalation of $\mathrm{H}_{2} \mathrm{SO}_{4}$ preceded a certain amount of time. Follow-up intercalation of $\mathrm{Na}_{2} \mathrm{SiO}_{3}$ was maintained some time and then the solid phase was washed with de-ionized water until $\mathrm{pH}$ of the waste water reached to 6.0-7.0. After dipping in water for $2 \mathrm{~h}$, filtrated and dried the sample at $50-60{ }^{\circ} \mathrm{C}$ for $4-5 \mathrm{~h}$, then expandable graphite was obtained.

Characterization of the samples: Expanded volume is an important factor to judge dilatability of expandable graphite and it is defined as the volume of $1.0 \mathrm{~g}$ expandable graphite after expansion at a certain temperature. The temperature corresponding to 1.5 times of initial volume of expandable graphite is defined as initiation expansion temperature. They were detected according to our previous work ${ }^{21}$.

XRD pattern was obtained on a Y-4Q X-ray diffractometer operating at $40 \mathrm{kV}, 30 \mathrm{~mA}$, employing Ni-filtered $\mathrm{CuK}_{\alpha}$ radiation with $2^{\circ}$ ranging from $20^{\circ}$ to $70^{\circ}$.

Preparation of flame retarded ethylene vinyl acetate copolymer (EVA) composites: A certain amount of flame retardant was added into melting EVA at $130{ }^{\circ} \mathrm{C}$ in Muller, the mixtures were pressed at $125^{\circ} \mathrm{C}$ and $10 \mathrm{MPa}$ and then chopped in slivers with a size of $120 \mathrm{~mm} \times 6 \mathrm{~mm} \times 3 \mathrm{~mm}$.

Detection of limiting oxygen index (LOI) of retarded EVA composites: Limiting oxygen index is the minimum amount of oxygen in an oxygen-nitrogen mixture required to support combustion over $3 \mathrm{~min}$. The incised slivers of retarded EVA composites were used to measure LOI according to Standard of GB/T2406-1993 with oxygen index instrument (Chengde, China).

SEM micrographs analysis of samples: To observe layer structures of natural graphite and expandable graphite and survey the combustion residues morphology of retardant compo-sites, SEM micrographs of these samples were detected with scanning electron microscope.

\section{RESULTS AND DISCUSSION}

Optimization of influence factor in the preparation of expandable graphite: Influence of various factors on dilatability of the expandable graphite were optimized through single factor tests including the dosages of $\mathrm{KMnO}_{4}, \mathrm{H}_{2} \mathrm{SO}_{4}$, $\mathrm{Na}_{2} \mathrm{SiO}_{3} \cdot 9 \mathrm{H}_{2} \mathrm{O}$ and $\mathrm{H}_{2} \mathrm{SO}_{4}$ concentration, $\mathrm{pH}$ of $\mathrm{Na}_{2} \mathrm{SiO}_{3}$ and $\mathrm{NaOH}$ mixed solution, reaction temperature, reaction time.

Influence of $\mathrm{H}_{2} \mathrm{SO}_{4}$ dosage on expandable graphite dilatability: As an important intercalating agent, $\mathrm{H}_{2} \mathrm{SO}_{4}$ dosage in reaction has obvious effect on expandable graphite dilatability. To investigate this feasible dosage, it was changed in the range of $2.5-4.5 \mathrm{~g} / \mathrm{g}$. In the following experiment, the operational program was the same as mentioned above. Mass ratio of $\mathrm{C}$ to $\mathrm{KMnO}_{4}$ was controlled as 1.0:0.2; $\mathrm{H}_{2} \mathrm{SO}_{4}$ was diluted to mass concentration of $65 \%$. Mixed solution of $\mathrm{Na}_{2} \mathrm{SiO}_{3}$ and $\mathrm{NaOH}$ containing $4 \mathrm{~g} \mathrm{Na}_{2} \mathrm{SiO}_{3}$ and with a $\mathrm{pH}$ of 13 was added dropwise when the intercalation of $\mathrm{H}_{2} \mathrm{SO}_{4}$ preceded $2.5 \mathrm{~min}$. The reactions maintained $40 \mathrm{~min}$ at $40{ }^{\circ} \mathrm{C}$. Fig. 1 illustrate that feasible mass ratio of $\mathrm{H}_{2} \mathrm{SO}_{4}$ to graphite should be $4.0 \mathrm{~g} / \mathrm{g}$. Under this ratio, expanded volume of expandable graphite can reach $300 \mathrm{~mL} / \mathrm{g}$. Insufficiency $\mathrm{H}_{2} \mathrm{SO}_{4}$ dosage would cause an incomplete intercalation and leading to the decrease of dilatability; Superfluous $\mathrm{H}_{2} \mathrm{SO}_{4}$ would cause the relative scarcity of $\mathrm{KMnO}_{4}$ and incomplete oxygenation for graphite.

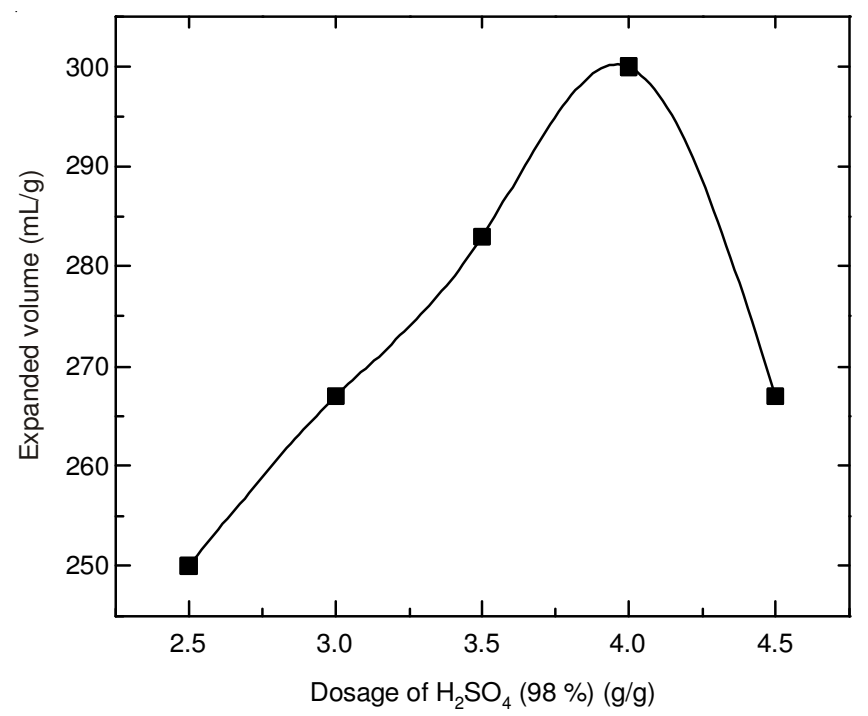

Fig. 1. Influence of $\mathrm{H}_{2} \mathrm{SO}_{4}$ dosage on expanded volume of expandable graphite

Influence of $\mathrm{H}_{2} \mathrm{SO}_{4}$ concentration on expandable graphite dilatability: Under mass ratio C: $\mathrm{KMnO}_{4}: \mathrm{H}_{2} \mathrm{SO}_{4}$ 
(98\%) of 1.0:0.2:4.0, influence of $\mathrm{H}_{2} \mathrm{SO}_{4}$ mass concentration in the range of $65-85 \%$ on expandable graphite dilatability was detected. Other conditions were controlled the same as mentioned above. As shown in Fig. 2, expanded volume of expandable graphite increases with mass concentration of $\mathrm{H}_{2} \mathrm{SO}_{4}$ at first and then decreases when it is beyond $75 \%$. According to eqn (1), the oxidation ability of $\mathrm{KMnO}_{4}$ is affected by hydrogen ion effective concentration $\left[\mathrm{H}^{+}\right]$. Too lower or too higher $\mathrm{H}_{2} \mathrm{SO}_{4}$ concentration in reaction can all lead to the decrease of $\left[\mathrm{H}^{+}\right]$and oxidation ability $\mathrm{KMnO}_{4}$, then cause insufficient intercalation of $\mathrm{H}_{2} \mathrm{SO}_{4}$ and $\mathrm{Na}_{2} \mathrm{SiO}_{3}$. Feasible mass concentration of $\mathrm{H}_{2} \mathrm{SO}_{4}$ in reaction can be set as $75 \%$.

$$
\begin{aligned}
\mathrm{E}_{\mathrm{MnO}_{4}-/ \mathrm{Mn}^{2+}=} & \mathrm{E}_{\mathrm{MnO}_{4}^{-} / \mathrm{Mn}^{2+}+(0.05916 / 5)}^{+} \\
& \lg \left\{\left[\mathrm{H}^{+}\right]^{8}\left[\mathrm{MnO}_{4}^{-}\right] /\left[\mathrm{Mn}^{2+}\right]\right\}
\end{aligned}
$$

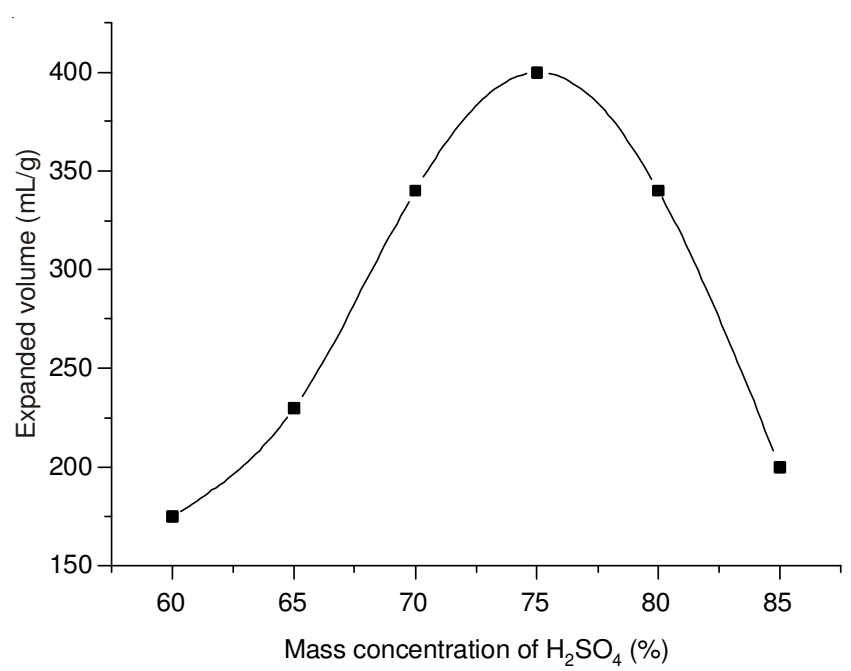

Fig. 2. Influence of $\mathrm{H}_{2} \mathrm{SO}_{4}$ mass concentration on expanded volume of expandable graphite

Influence of $\mathrm{KMnO}_{4}$ dosage on expandable graphite dilatability: In intercalating reaction of natural graphite, $\mathrm{KMnO}_{4}$ acts as an oxidant to capture electrons between graphene planes structure and then leads to the formation of the graphite carbon cations and subsequent intercalation of $\mathrm{H}_{2} \mathrm{SO}_{4}$ and $\mathrm{Na}_{2} \mathrm{SiO}_{3}$. In order to investigate its influence on dilatability in two step intercalation, single-factor experiments were carried out by changing $\mathrm{KMnO}_{4}$ dosage in the range of $0.17-0.40 \mathrm{~g} / \mathrm{g}$. Experiments were carried out under the mass ratio $\mathrm{C}: \mathrm{H}_{2} \mathrm{SO}_{4}(98 \%)$ of 1.0:4.0, $\mathrm{H}_{2} \mathrm{SO}_{4}$ was diluted to mass concentration of $75 \%$ and other conditions were controlled the same as mentioned above. Fig. 3 illustrate that when the mass ratio of $\mathrm{KMnO}_{4}$ to graphite is controlled as $0.22 \mathrm{~g} / \mathrm{g}$, the prepared expandable graphite possesses a maximum expanded volume of $466 \mathrm{~mL} / \mathrm{g}$. Insufficiency $\mathrm{KMnO}_{4}$ would cause an incomplete oxygenation of graphite and superfluous $\mathrm{KMnO}_{4}$ would cause an excessive oxygenation, which would lead to a decrease of expandable graphite granularity and its expanded volume. The feasible dosage of $\mathrm{KMnO}_{4}$ can be set as $0.22 \mathrm{~g} / \mathrm{g}$.

Influence of $\mathrm{Na}_{2} \mathrm{SiO}_{3}$ dosage on expandable graphite dilatability: Under mass ratio $\mathrm{C}: \mathrm{KMnO}_{4}: \mathrm{H}_{2} \mathrm{SO}_{4}(98 \%)$ of 1.0:0.22:4.0, $\mathrm{H}_{2} \mathrm{SO}_{4}$ was diluted to mass concentration of $75 \%$ before reaction and other conditions were controlled the same as mentioned above. The influence of $\mathrm{Na}_{2} \mathrm{SiO}_{3} \cdot 9 \mathrm{H}_{2} \mathrm{O}$ dosage, dissolved in $2 \mathrm{~mL}$ aqueous solution of $\mathrm{NaOH}$ with a concen- tration of $0.1 \mathrm{~mol} / \mathrm{L}$, was detected in the range of $0-1.2 \mathrm{~g}$. As an assistant intercalating agent, increase of its dosage can improve expandable graphite dilatability as shown in Fig. 4. When it is controlled as $0.8 \mathrm{~g}$, expandable graphite with a maximum expanded volume of $517 \mathrm{~mL} / \mathrm{g}$ can be gained. Superfluous dosage would cause the relative scarcity of $\mathrm{KMnO}_{4}$ oxidation ability and incomplete oxygenation of graphite.

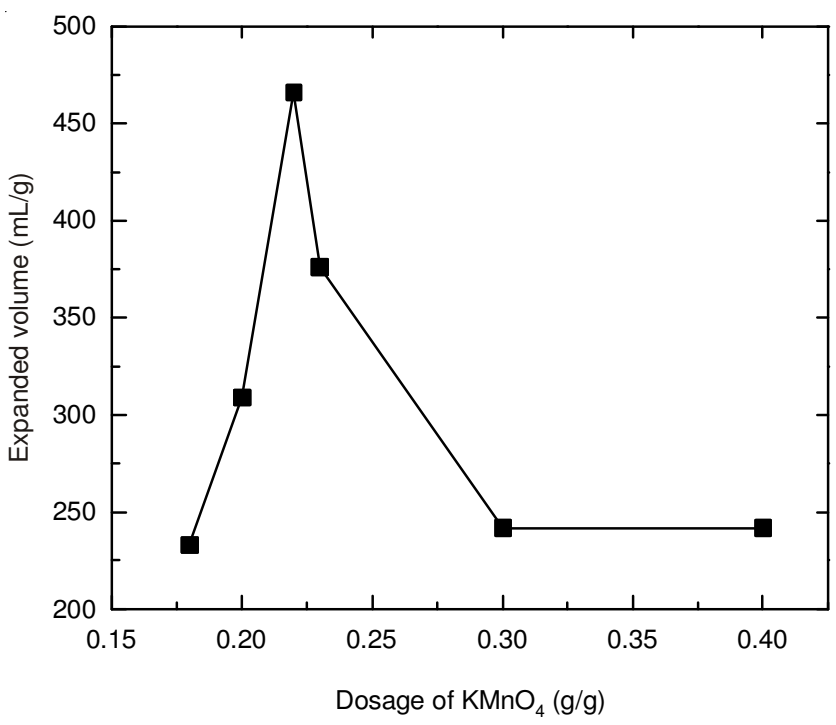

Fig. 3. Influence of $\mathrm{KMnO}_{4}$ dosage on expanded volume of expandable graphite

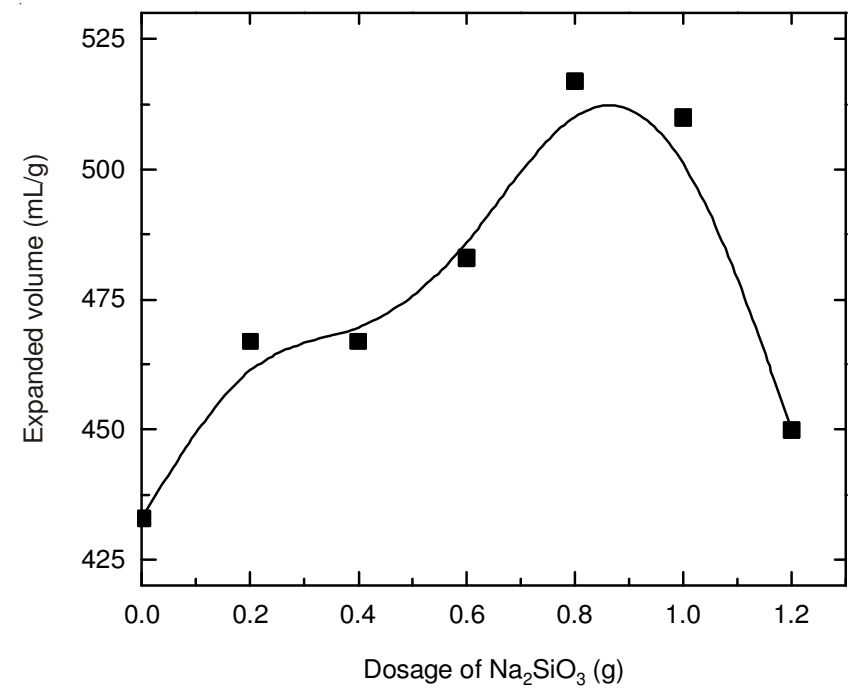

Fig. 4. Influence of $\mathrm{Na}_{2} \mathrm{SiO}_{3}$ dosage on expanded volume of expandable graphite

Influence of pH of aqueous solution of $\mathrm{NaOH}$ on expandable graphite dilatability: Under mass ratio C: $\mathrm{KMnO}_{4}: \mathrm{H}_{2} \mathrm{SO}_{4}$ (98\%) of 1.0:0.22:4.0, $\mathrm{H}_{2} \mathrm{SO}_{4}$ was diluted to the mass concentration of $75 \%$ before reaction. Mixed solution of $\mathrm{Na}_{2} \mathrm{SiO}_{3}$ and $\mathrm{NaOH}$ (containing $0.8 \mathrm{~g} \mathrm{Na}_{2} \mathrm{SiO}_{3}$ in $2.0 \mathrm{~mL} \mathrm{NaOH}$ aqueous solution) with different $\mathrm{pH}$ was added dropwise when the intercalation of $\mathrm{H}_{2} \mathrm{SO}_{4}$ preceded $2.5 \mathrm{~min}$ and other conditions were controlled the same as mentioned above. Influence of $\mathrm{pH}$ of aqueous solution of $\mathrm{NaOH}$ on expandable graphite dilatability was detected and shown as Fig. 5. It can be seen that $\mathrm{pH}$ of aqueous solution of $\mathrm{NaOH}$ has obvious influence 
on expanded volume. When the $\mathrm{pH}$ is low, there are insufficient $\mathrm{OH}^{-}$ions to neutralize the superfluous $\mathrm{H}^{+}$in solution, then lead to the formation of $\mathrm{H}_{2} \mathrm{SiO}_{3}$ sediment and decrease the effective intercalation of $\mathrm{Na}_{2} \mathrm{SiO}_{3}$. High $\mathrm{pH}$ causes the decrease of $\mathrm{KMnO}_{4}$ oxidation ability and incompletely open the graphite layers and intercalate substances. In order to get a high dilatability, $\mathrm{pH}$ of aqueous solution of $\mathrm{NaOH}$ should be controlled 13 .

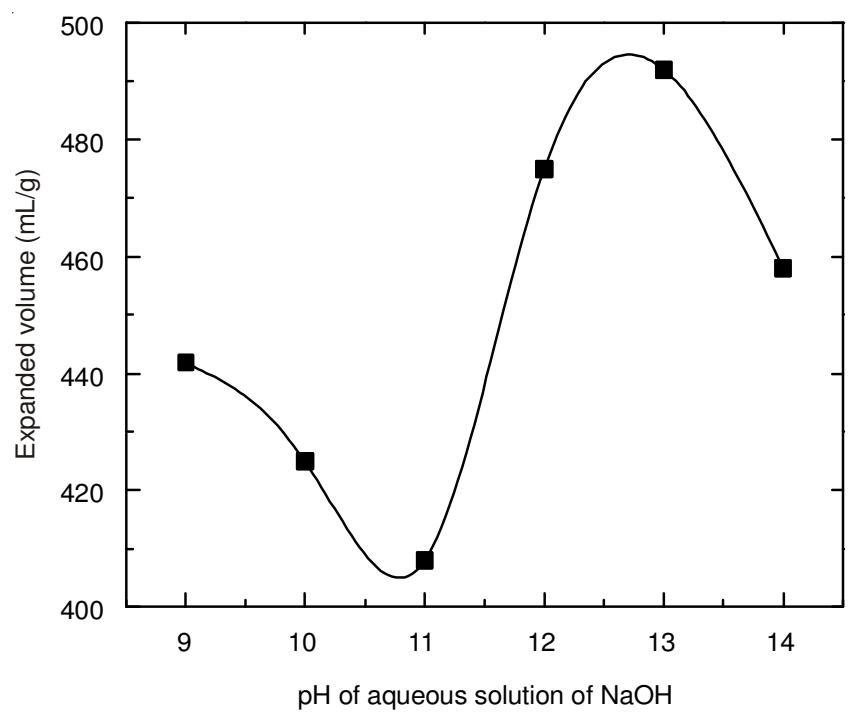

Fig. 5. Influence of $\mathrm{pH}$ of aqueous solution of $\mathrm{NaOH}$ on expanded volume of expandable graphite

Influence of the first-step reaction preceded time on expandable graphite dilatability: In view of the poor solubility of silicate in acid medium, $\mathrm{Na}_{2} \mathrm{SiO}_{3}$ dissolved in aqueous solution of $\mathrm{NaOH}$ was used. At the same time, a twostep intercalating method was performed to ensure $\mathrm{KMnO}_{4}$ oxidation ability and preferentially intercalation of $\mathrm{H}_{2} \mathrm{SO}_{4}$. Conditions were controlled the same as mentioned above, mixed solution of $\mathrm{Na}_{2} \mathrm{SiO}_{3}$ and $\mathrm{NaOH}$ containing $0.8 \mathrm{~g} \mathrm{Na}_{2} \mathrm{SiO}_{3}$ and with a $\mathrm{pH}$ of 13 was dropwise added when the intercalation of $\mathrm{H}_{2} \mathrm{SO}_{4}$ preceded 2.5, 5, 7.5, 10 and $15 \mathrm{~min}$, respectively. Influence of the first-step reaction preceded time on expandable graphite dilatability was shown as Fig. 6.

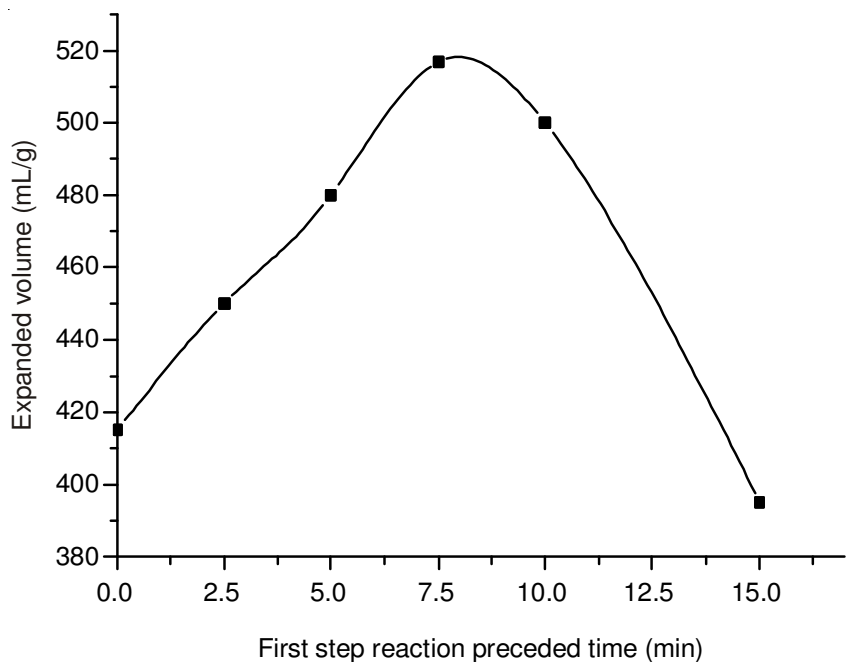

Fig. 6. Influence of the first-step preceded reaction time on expanded volume of expandable graphite
Results show that the expanded volume increases with the increase of the first-step reaction preceded time at first and then decreases with the further increase of preceded time. When mixture of $\mathrm{Na}_{2} \mathrm{SiO}_{3}$ and $\mathrm{NaOH}$ is added dropwise together with $\mathrm{H}_{2} \mathrm{SO}_{4}, \mathrm{OH}^{-}$would consume a part of $\mathrm{H}^{+}$, which would cause the decline of $\mathrm{KMnO}_{4}$ oxidation ability and then further influence the gap between graphite layers and intercalation of $\mathrm{H}_{2} \mathrm{SO}_{4}$ and $\mathrm{Na}_{2} \mathrm{SiO}_{3}$. So a step-by-step intercalation of $\mathrm{H}_{2} \mathrm{SO}_{4}$ and $\mathrm{Na}_{2} \mathrm{SiO}_{3}$ is needed. Increase of the first-step reaction preceded time leads expanded volume increases gradually. Intercalation of graphite includes oxidation, intercalation and change of graphite layers. When the first-step reaction proceeded for a feasible time, oxidation of graphite is almost completed, the gap between graphite layers is extended, the intercalating reaction of $\mathrm{H}_{2} \mathrm{SO}_{4}$ proceeds extensively and the successive addition and intercalation of $\mathrm{Na}_{2} \mathrm{SiO}_{3}$ increase total intercalating amount in graphite layers and dilatability of expandable graphite ${ }^{17}$. Oxidation, intercalation and layer structure change will be finished over time, when the addition of $\mathrm{Na}_{2} \mathrm{SiO}_{3}$ is too late. The intercalation and layer change of graphite will be finished, then expanded volume will decrease. According to the experimental results, feasible preceded time of the first-step reaction should be $7.5 \mathrm{~min}$.

Influence of reaction temperature on expandable graphite dilatability: Under mass ratio $\mathrm{C}: \mathrm{KMnO}_{4}: \mathrm{H}_{2} \mathrm{SO}_{4}$ (98\%) of 1.0:0.22:4.0; $\mathrm{H}_{2} \mathrm{SO}_{4}$ was diluted to the mass concentration of $75 \%$ before reaction; mixed solution of $\mathrm{Na}_{2} \mathrm{SiO}_{3}$ and $\mathrm{NaOH}$ containing $0.8 \mathrm{~g} \mathrm{Na}_{2} \mathrm{SiO}_{3}$ and with a $\mathrm{pH}$ of 13 was added dropwise when the intercalation of $\mathrm{H}_{2} \mathrm{SO}_{4}$ preceded 7.5 $\mathrm{min}$; reaction totally maintains $40 \mathrm{~min}$; the influence of reaction temperature on expanded volume (EV) was detected. When it is less than $40{ }^{\circ} \mathrm{C}$, the increase of temperature can improve expandable graphite dilatability as shown in Fig. 7. Too low temperature may cause low reaction speed and insufficient intercalation. While, too high temperature can lead the exothermic reaction releasing more heat and excessive oxygenation of graphite. The feasible reaction temperature can be set as $40{ }^{\circ} \mathrm{C}$.

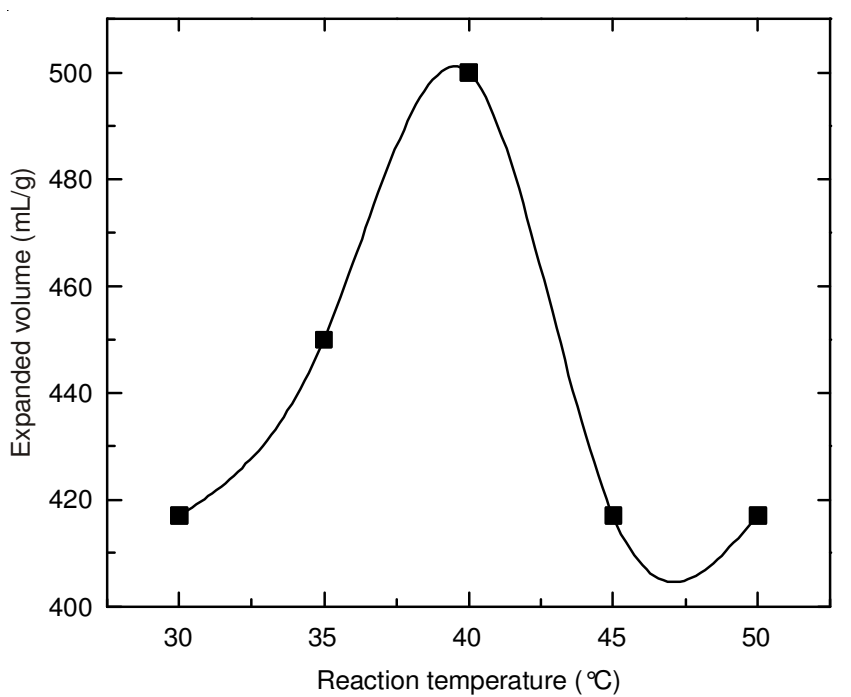

Fig. 7. Influence of reaction temperature on expanded volume of expandable graphite 
Feasible condition of preparation of expandable graphite: According to the experimental results, feasible conditions to prepare expandable graphite can be set as following: mass ratio of $\mathrm{C}, \mathrm{KMnO}_{4}$ and $\mathrm{H}_{2} \mathrm{SO}_{4}(98 \%)$ is 1.0:0.22:4.0; $\mathrm{H}_{2} \mathrm{SO}_{4}$ diluted to mass concentration of $75 \%$ before reaction; mixed solution of $\mathrm{Na}_{2} \mathrm{SiO}_{3}$ and $\mathrm{NaOH}$ containing $0.8 \mathrm{~g} \mathrm{Na}_{2} \mathrm{SiO}_{3}$ and with a $\mathrm{pH}$ of 13 is dropwise added when the intercalation of $\mathrm{H}_{2} \mathrm{SO}_{4}$ preceded $7.5 \mathrm{~min}$; reaction totally maintains $40 \mathrm{~min}$ at $40{ }^{\circ} \mathrm{C}$. The solid obtained through filtration is dried at $50-60{ }^{\circ} \mathrm{C}$ for 4-5 $\mathrm{h}$ and then expandable graphite is obtained. Its initial expansion temperature and expanded volume are detected as $202{ }^{\circ} \mathrm{C}$ and $517 \mathrm{~mL} / \mathrm{g}$ (at $800{ }^{\circ} \mathrm{C}$ ), respectively.

Preparation of the blank expandable graphite without $\mathrm{Na}_{2} \mathrm{SiO}_{3}$ intercalation: Compared with expandable graphite, the blank expandable graphite $\left(\mathrm{EG}_{1}\right)$ is prepared under mass ratio $\mathrm{C}: \mathrm{KMnO}_{4}: \mathrm{H}_{2} \mathrm{SO}_{4}(98 \%)$ of 1.0:0.22:4.0, $\mathrm{H}_{2} \mathrm{SO}_{4}$ is diluted to the mass concentration of $75 \%$ before reaction and reaction maintains $40 \mathrm{~min}$ at $40{ }^{\circ} \mathrm{C}$. It's initial expansion temperature and expanded volume is detected as $235^{\circ} \mathrm{C}$ and $433 \mathrm{~mL} / \mathrm{g}$ (at $800{ }^{\circ} \mathrm{C}$ ), respectively. It is obvious that $\mathrm{Na}_{2} \mathrm{SiO}_{3}$ obviously affect initial expansion temperature and dilatability of expandable graphite, addition of $0.8 \mathrm{~g} / \mathrm{g}$ of this assistant intercalating agent in graphite intercalating reaction can cause an increase of $19 \%$ of expanded volume. The expandable graphite shows better flame retardancy than blank expandable graphite for its good dilatability.

XRD analysis of the prepared samples: XRD analysis for natural graphite and expandable graphite were performed. As shown in Fig. 8(a), the two peaks with the interplanar crystal spacing of $3.34 \AA$ and $1.67 \AA$ corresponding to diffraction angle of $26.6^{\circ}, 54.8^{\circ}$ are the characteristic spectrum of natural graphite. While, as shown in Fig. 8(b), the characteristic peaks of expandable graphite transfer to a small angle of $26.4^{\circ}$ and it corresponds to a big interplanar crystal spacing of $3.40 \AA$ due to intercalation in graphene planes. Natural graphite is oxidized under oxidation of $\mathrm{KMnO}_{4}$ and carried on positive charge. Due to the distortion of conjugate system and the exclusive function of positive charge, the gap between graphite layers is extended ${ }^{2}$, the intercalating reaction can proceed extensively between graphite and intercalating agent. A new reflection peak caused by the intercalation of $\mathrm{Na}_{2} \mathrm{SiO}_{3}$ can be observed at $28.6^{\circ}$ with a crystal spacing of $3.12 \AA$. Compared with standard XRD chart, it indicates that the possible existing form of $\mathrm{Si}$ is $\mathrm{SiO}_{2}$ or sodium silicate. For the known flame retardancy of $\mathrm{SiO}_{2}$ and sodium silicate, it can be forecast that expandable graphite will present better flame retardancy than the contrast blank expansible graphite.

Detection of expandable graphite anti-flame capability for EVA: Processing temperature of EVA is normally $130{ }^{\circ} \mathrm{C}$, so the prepared expandable graphite and blank expansible graphite can be used as flame retardant and they are added to the polymer according to the proportion listed in Table-1. LOI was detected according to the mentioned method. The results show that LOI of single EVA is only $19.3 \%$ and its combustion accompanies with molten drop at the same time. Addition of $30 \%$ blank expansible graphite can make LOI improve to $24.4 \%$, no molten drop occurs. Whereas, the addition of the same amount of expandable graphite to EVA can make LOI reach $28.5 \%$ and no molten drop occurs too. The results

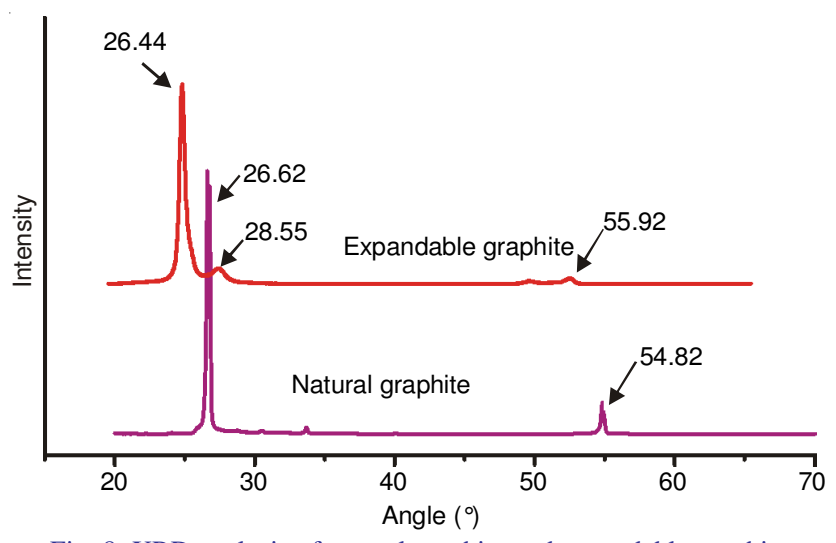

Fig. 8. XRD analysis of natural graphite and expandable graphite

indicate that the use of $\mathrm{Na}_{2} \mathrm{SiO}_{3} \cdot 9 \mathrm{H}_{2} \mathrm{O}$ in intercalating reaction of graphite can improve flame retardancy for EVA. Furthermore, comparing sample 3 with sample 4 , it is find that the intercalated silicate is more effectual in improving the flame retardancy than the direct addition of $\mathrm{Na}_{2} \mathrm{SiO}_{3} \cdot 9 \mathrm{H}_{2} \mathrm{O}$.

\begin{tabular}{cccccc}
\multicolumn{7}{c}{ LOI OF THE FLAME RETARDED EVA COMPOSITES } \\
\cline { 2 - 5 } Sample & EVA & $\begin{array}{c}\text { Fxpandable } \\
\text { graphite }\end{array}$ & $\begin{array}{c}\text { Blank } \\
\text { expandable } \\
\text { graphite }\end{array}$ & $\mathrm{Na}_{2} \mathrm{SiO}_{3} \cdot 9 \mathrm{H}_{2} \mathrm{O}$ & $\begin{array}{c}\text { LOI } \\
(\%)\end{array}$ \\
\cline { 2 - 5 } & 100 & 0 & 0 & 0 & 19.3 \\
2 & 70 & 0 & 30 & 0 & 24.4 \\
3 & 70 & 30 & 0 & 0 & 28.5 \\
4 & 70 & 0 & 13 & 17 & 25 \\
\hline
\end{tabular}

SEM analysis of samples: Fig. 9 presents SEM micrographs of natural graphite, expandable graphite and the combustion residues of retardant composites. Comparing Fig. 9 (a) with Fig. 9 (b), the layers' structures of natural graphite are

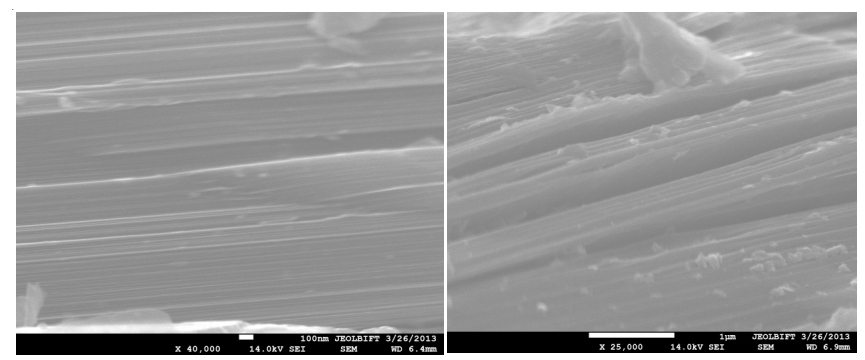

(a) $\times 40,000$

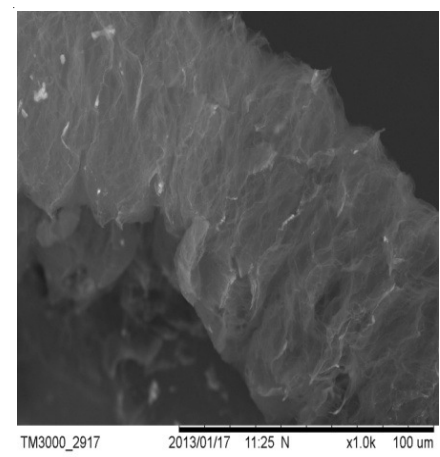

(c) $\times 1,000$ (b) $\times 25,000$

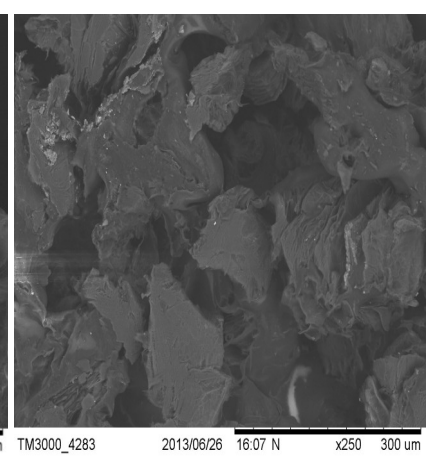

(d) $\times 250$
Fig. 9. SEM micrographs of samples, (a) Natural graphite (b) expandable graphite (c) Worm-like expanded graphite particle (d) Section of EVA/expandable graphite composites combustion residues 
compact and the layers' distance is very small in Fig. 9 (a). After the graphite is oxidized and intercalated, the layers distance has been enlarged and the boundary layers of Fig. 9 (b) have been loosed while the forces between the layers disappear. As can be seen in Fig. 9 (c) and (d), when expandable graphite touches with fire, it absorbs heat and turns into worm-like expanded graphite particles and the inserted agents release $\mathrm{CO}_{2}, \mathrm{H}_{2} \mathrm{O}$ gas and escape from the expandable graphite. Clearly, EVA/expandable graphite composite takes place dramatically expansion and the layers of graphite protect the polymer matrix to avoid further thermal degradation. It results in the promotion of flame retardancy property of the composites.

\section{Conclusion}

Control reaction conditions as following: $\mathrm{C}, \mathrm{KMnO}_{4}$ and $\mathrm{H}_{2} \mathrm{SO}_{4}(98 \%)$ is with the mass ratio of 1.0:0.22:4.0; $\mathrm{H}_{2} \mathrm{SO}_{4}$ is diluted to the mass concentration of $75 \%$ before reaction; mixed solution of $\mathrm{Na}_{2} \mathrm{SiO}_{3}$ and $\mathrm{NaOH}$ containing $0.8 \mathrm{~g} \mathrm{Na}_{2} \mathrm{SiO}_{3}$ and with a $\mathrm{pH}$ of 13 is dropwise added when the intercalation of $\mathrm{H}_{2} \mathrm{SO}_{4}$ preceded $7.5 \mathrm{~min}$; reaction totally maintains $40 \mathrm{~min}$ at $40{ }^{\circ} \mathrm{C}$. We can prepare expandable graphite flame retardant with an initial expansion temperature of $202^{\circ} \mathrm{C}$ and maximum expanded volume of $517 \mathrm{~mL} / \mathrm{g}$. The intercalating silicate has obvious influence on expandable graphite dilatability and flame retardancy. Feasible intercalating dosage can increase its expanded volume and flame retardant capability. The excellent anti-flame capability of expandable graphite is contributed by the ability of absorbing enormous amount heat and forming swollen multicellular carbonaceous char. The intercalating silicate is more effectual in improving the flame retardancy than the direct addition of $\mathrm{Na}_{2} \mathrm{SiO}_{3} \cdot 9 \mathrm{H}_{2} \mathrm{O}$.

\section{REFERENCES}

1. R.C. Li, CN Patent 19931068152A (1993).

2. C.F. Kuan, K.C. Tsai, C.H. Chen, H.C. Kuan, T.Y. Liu and C.L. Chiang, Polym. Compos., 33, 872 (2012).

3. X.Y. Pang and J.H. Liu, Asian J. Chem., 22, 3014 (2010).

4. X.Y. Pang, L.J. Xu and L.L. Zhang, Asian J. Chem., 24, 382 (2012).

5. R.C. Xie and B. Qu, J. Appl. Polym. Sci., 80, 1190 (2001).

6. J. Li, J. Li and M. Li, Mater. Lett., 62, 2047 (2008).

7. M. Thirumal, D. Khastgir, N.K. Singha, B.S. Manjunath and Y.P. Naik, J. Appl. Polym. Sci., 110, 2586 (2008).

8. X.G. Zhang, L.L. Ge, W.Q. Zhang, J.H. Tang, L. Ye and Z.M. Li, J. Appl. Polym. Sci., 122, 932 (2011).

9. R.C. Xie and B.J. Qu, Polym. Degrad. Stab., 71, 375 (2001).

10. H.F. Zhu, Q.L. Zhu, J. Li, K. Tao, L.X. Xue and Q. Yan, Polym. Degrad. Stab., 96, 183 (2011).

11. X.C. Bian, J.H. Tang, Z.M. Li, Z.Y. Lu and A. Lu, J. Appl. Polym. Sci., 104, 3347 (2007).

12. L. Ye, X.Y. Meng, X. Ji, Z.M. Li and J.H. Tang, Polym. Degrad. Stab., 94, 971 (2009).

13. H. Shioyama and R. Fujii, Carbon, 25, 771 (1987).

14. X.Y. Pang, S.K. Zhi, Y.J. Su, L. Liu and F. Lin, J. Hebei Univ. Nat. Sci., 31, 497 (2011).

15. K.M. Song, W.Y. Lu, S.Y. Gao and Q.Y. Yan, Chinese J. Appl. Chem., 12, 94 (1995)

16. V.S. Leshin, N.E. Sorokina and V.V. Avdeev, Russ. J. Electrochem., 41, 572 (2005).

17. Z.D. Han, D.W. Zhang, L.M. Dong and X.Y. Zhang, Chinese J. Inorg. Chem., 23, 286 (2007).

18. X.Y. Pang, M.K. Song, Y. Tian and M.W. Duan, J. Chil. Chem. Soc., 57, 1318 (2012).

19. M. Zanetti and L. Costa, Polymer, 45, 4367 (2004).

20. Z. Hu, L. Chen, B. Zhao, Y. Luo, D.Y. Wang and Y.Z. Wang, Polym. Degrad. Stab., 96, 320 (2011).

21. X.Y. Pang, Y. Tian, M.W. Duan and M. Zhai, Cent. Eur. J. Chem., 11, 953 (2013). 